\title{
PENGARUH PENDIDIKAN KEBENCANAAN BANJIR BANDANG TERHADAP KESIAPSIAGAAN MAHASISWA PROGRAM STUDI ILMU KEPERAWATAN FK UNSRAT
}

\author{
Muhamad Nurmansyah \\ Andi Buanasari \\ Program Studi Ilmu Keperawatan Fakultas Kedokteran \\ Universitas Sam Ratulangi \\ Email: andi.buanasari@unsrat.ac.id
}

\begin{abstract}
Flash flood is one of the most frequent disasters in Indonesia. The city of Manado was included in the event of the worst banjir bandang disaster. Preparedness greatly impacts on disasters that occur. Given the sudden onset of disaster and detrimental to many aspects, preparedness is needed to anticipate disasters. Therefore we need emergency education and simulation training to improve preparedness. Location of research for students who live in prone to flash flood disasters. The aim was to determine the effect of flash flood disaster education on the preparedness of nursing science students in FK Unsrat. The research design was using a nonrandomized control group pretest - posttest design. Samples were 32 people using consecutive sampling technique. Methods of collecting data using knowledge and attitude questionnaires, early warning systems, emergency response plans and resource mobilization to measure respondent preparedness and statistical tests using the Wilcoxon test and Man Whitney test. The results of the study obtained a P-Value of $0,000(\leq \alpha=0.05)$ which means that there is a significant difference. The conclusions of the results of this study indicate an increase in preparedness in nursing students after being given counseling and emergency simulation training.
\end{abstract}

Keywords: Disaster Education, Flash Flood, Preparedness

\begin{abstract}
Abstrak: Banjir bandang adalah salah satu bencana yang paling sering terjadi di Indonesia. Kota Manado masuk dalam peristiwa bencana banjir bandang terparah. Kesiapsiagaan sangat berdampak terhadap bencana yang terjadi. Mengingat bencana yang datangnya secara mendadak dan merugikan banyak aspek, kesiapsiagaan sangat diperlukan untuk mengantisipasi bencana. Oleh sebab itu diperlukan pendidikan kebencanaan dan pelatihan simulasi darurat untuk meningkatkan kesiapsiagaan. Lokasi tempat penelitian pada mahasiswa yang tinggal di daerah rawan bencana banjir bandang. Tujuan untuk mengetahui pengaruh pendidikan kebencanaan banjr bandang terhadap kesiapsiagaan mahasiswa program studi ilmu keperawatan FK Unsrat. Metode penelitian yaitu menggunakan desain nonrandomized control group pretest - posttest design. Sampel berjumlah 32 orang menggunakan teknik consecutive sampling. Metode pengumpulan data menggunakan kuesioner pengetahuan dan sikap, sistem peringatan dini, rencana tanggap darurat dan mobilisasi sumber daya untuk mengukur kesiapsiagaan responden dan uji statistik menggunakan uji Wilcoxon dan uji Man Whitney. Hasil penelitian di dapat nilai $P$ - Value sebesar $0,000(\leq \alpha=0,05)$ yang berarti ada perbedaan yang signifikan. Simpulan hasil penelitian ini menunjukkan adanya peningkatan kesiapsiagaan pada mahasiswa keperawatan setelah diberikan penyuluhan dan pelatihan simulasi darurat.
\end{abstract}

Kata kunci : Pendidikan Kebencanaan, Banjir Bandang, Kesiapsiagaan 


\section{PENDAHULUAN}

Indonesia adalah Negara yang rawan bencana, mengingat kondisi geografi dan geologi Indonesia yang terletak pada pertemuan tiga lempeng raksasa, Eurasia, Indoaustralia, dan pasifik (Ruswandi, 2014). Salah satu bencana terbesar yang sering terjadi di Indonesia adalah bencana banjir bandang. Banjir bandang adalah banjir yang datang secara tiba-tiba dengan debit air yang besar yang disebabkan terbendungnya aliran sungai pada alur sungai (Badan Nasional Penanggulangan Bencana, 2011). Prevalensi kejadian banjir bandang di Indonesia, tahun 2013, di Bohorok Sumatera Utara, korban kurang lebih 300 orang, lebih dari 400 rumah hancur, turun hujan selama 2-5 jam. Tahun 2010 di Wasior Papua Barat, 153 orang meninggal, 157 orang hilang, 1473 rumah rusak berat, turun hujan selama 10 jam. Tahun 2006 Jember Jawa Timur, korban 119 orang, 264 rumah hanyut, turun hujan selama 3 hari berturut-turut (Adi, 2013).

Banjir bandang tergolong dalam banjir besar sehingga dampaknya menimbulkan kerugian. Banjir bandang tidak hanya menimbulkan kerugian materi saja namun banyak kerugian besar lainnya seperti kecacatan dan kematian (Ilmu Geografi Indonesia, 2016). Dampak bencana banjir bandang juga sangat berpengaruh bagi psikologis setiap orang yang mengalaminya. (Laluyan, 2012). Sebagai Ibukota Provinsi Sulawesi Utara, Kota Manado termasuk kota besar dalam hal pembangunan. Dampaknya terjadi penurunan kualitas lingkungan dan bencana alam bagi kota Manado. Banjir bandang adalah salah satu bencana yang pernah terjadi di Kota Manado. Tepat pada tahun 2014, banjir bandang paling terparah melanda Kota Manado (Hendrik, 2016). Dalam hal ini Sumber Daya Manusia (SDM) yang memiliki kompetensi sangat berpengaruh dalam kesiapsiagaan bencana (Depkes, 2006).

Kesiapsiagaan pelayanan kesehatan termasuk kegiatan mencari informasi tentang ancaman/bahaya (Analis
Kerentanan Bencana), merencanakan respons yang terorganisir untuk kondisi kegawatdaruratan, menyediakan pelatihan kesiapsiagaan kegawatdaruratan bencana, melakukan latihan dan simulasi kegawatdaruratan untuk menilai perencanaan-perencanaan dan hasil pelatihan, memperoleh dan mempertahankan peralatan dan fasilitasfasilitas kegawatdaruratan, menjalin perjanjian koordinasi antarpemerintah/antar-departemen, melakukan pendidikan pada masyarakat tentang kegawatdaruratan (Kurniati, dkk, 2018). Salah satu upaya Pemerintah Provinsi, dengan pembangunan Gedung Pusat Pengendalian Operasi Penanggulangan Bencana. Hal ini sebagai salah satu upaya peningkatan kesiapsiagaan dalam penanggulangan bencana serta penurunan Indeks Risiko Bencana (Pikiran Rakyat, 2016).

Upaya dari peneliti dalam penelitian ini adalah dengan pemberian pendidikan kebencanaan banjir bandang kepada peserta didik keperawatan dengan tujuan meningkatkan sumber daya bencana dalam kesiapsiagaan bencana banjir bandang. Penelitian ini di khususkan kepada peserta didik keperawatan yang daerah tempat tinggalnya beresiko akan bencana. Alasan penelitian ini di berikan pada mahasiswa keperawatan karena mahasiswa keperawatan semester 1 dan semester 5 belum pernah mendapat modul mata kuliah gawat darurat bencana dan pelatihan gawat darurat bencana, sesuai dengan data yang peneliti terima saat pengambilan data awal, tanggal 10 september 2018. Penelitian yang akan di teliti lagi oleh peneliti ini diharapkan akan mendapat perkembangan yang lebih baik dari peserta didik keperawatan dalam kesiapsiagaan dan membangkitkan semangat untuk meningkatkan pendidikan kebencanaan banjir bandang terhadap kesiapsiagaan. 


\section{METODE PENELITIAN}

Rancangan penelitian ini adalah kuantitatif menggunakan quasi eksperimental design dengan menggunakan rancangan the nonrandomized control group pretest - posttest design . Observasi dilakukan dua kali yaitu sebelum eksperimen (O1) disebut pretest, dan sesudah eksperimen (O2) disebut dengan posttest (Septian, 2017). Adapun kerangka konsep pada penelitian ini terdiri atas variabel independen yaitu Pendidikan Kebencanaan Banjir Bandang dan variabel dependen adalah Kesiapsiagaan (Natoatmodjo, 2010).

Desain penelitian yang digunakan adalah metode cross sectional, dimana pengaruh pendidikan kebencanaan banjir bandaang (variabel independen) terhadap kesiapsiagaan (variabel dependen). Penelitian ini telah dilakukan di Program Studi Ilmu Keperawatan FK Unsrat khususnya pada mahasiswa yang daerah tempat tinggalnya rawan akan bencana, pada bulan November - Desember 2018. Populasi dalam penelitian ini adalah mahasiswa keperawatan FK Unsrat. Populasi dalam penelitian ini adalah mahasiswa semester 1 dan semester 5 Program Studi Ilmu Keperawatan FK Unsrat.

Teknik pengambilan sampel ditentukan dengan rumus consecutive sampling sehingga sampel yang digunakan dalam penelitian ini berjumlah 32 orang yang masing-masing kelompok berjumlah 16 orang. Instrumen pada penelitian ini meliputi empat hal yaitu pengetahuan dan sikap, sistem peringatan dini, rencana tanggap darurat dan mobilisasi sumber daya, dengan jumlah pernyataan 20 dan rincian pernyataan no $1-5$ berisi tentang pengetahuan dan sikap, 6-10 sistem peringatan dini, 11-15 berisi rencana tanggap darurat dan $16-20$ berisi mobilisasi sumber daya.

Analisis data yang digunakan pada penelitian ini yaitu analisis univariat dan analisa bivariat. Dalam analisis univariat selain karakteristik responden, peneliti juga melakukan analisis univariat untuk melihat kesiapsiagaan pada kelompok intervensi dan kelompok kontrol sdengan ketentuan, hasil kuesioner di tarik nilai median untuk melihat kesiapsiagaan, nilai keusioner lebih dari 17 dinyatakan siap, kurang dari 17 dinyatakan tidak siap. Cara menentukan nilai median dilihat dari jumlah jawaban kuesioner setiap kelompok. Dan untuk analisis bivariat dalam penelitian ini data dianalisis menggunakan metode statistik dengan skala numerik. Uji statistik yang dilakukan untuk menganalisis data dalam penelitian ini menggunakan uji Wicoxon dan Mann Withney. Adapun pengujian yang menggunakan uji statistik Wilcoxon yaitu untuk membandingkan kesiapsiagaan pretest dan posttest dari kedua kelompok sedangkan uji statistik Mann Withney untuk membandingkan kesiapsiagaan posttest dari kedua kelompok. (Ghozali, 2009). Dalam penelitian ini peneliti menggunakan etika penelitian yang bertujuan untuk menjaga kerahasiaan identitas responden akan kemungkinan terjadi ancaman terhadap responden (Jacklin, 2015).

\section{HASIL dan PEMBAHASAN}

\section{A. Karakteristik Responden}

Tabel 1. Distribusi Responden Berdasarkan Umur

\begin{tabular}{ccc}
\hline Umur & n & \% \\
\hline$<17$ Tahun & 6 & 18.8 \\
$>17$ Tahun & 26 & 81.3 \\
\hline Total & 32 & 100.0 \\
\hline
\end{tabular}

Berdasarkan tabel 1 diatas menjelaskan bahwa dari 32 reponden didapatkan sebagian besar responden berumur $>17$ tahun sebanyak 26 responden $(81,3 \%)$. 
Tabel 2. Distribusi Responden Berdasarkan Jenis Kelamin

\begin{tabular}{lcc}
\hline Jenis Kelamin & n & \% \\
\hline Laki-Laki & 3 & 9.4 \\
Perempuan & 29 & 90.6 \\
\hline Total & 32 & 100.0 \\
Sumber: Data Primer & 2019 &
\end{tabular}

Distribusi pada tabel 2 menjelaskan bahwa dari 32 responden didapatkan sebagian besar responden dengan jenis kelamin perempuan sebanyak 29 responden $(90,6)$.

Tabel 3. Distribusi Responden Berdasarkan Daerah Tempat Tinggal

\begin{tabular}{lll}
\hline Daerah Tempat Tinggal & $(\mathbf{n})$ & $(\boldsymbol{\%})$ \\
\hline Kec Singkil & 2 & 6.3 \\
Kec Tikala & 4 & 12.5 \\
Kec Paal 2 & 6 & 18.8 \\
Kec Tuminting & 4 & 12.5 \\
Kec Romboken & 2 & 6.3 \\
Kec Wanea & 5 & 15.6 \\
Kec Malalayang & 5 & 15.6 \\
Kec Tomohon Barat & 1 & 3.1 \\
Kec Tombariri & 1 & 3.1 \\
Kec Sario & 1 & 3.1 \\
Kec Wenang & 1 & 3.1 \\
Total & 32 & 100.0 \\
\hline
\end{tabular}

Sumber: Data Primer 2019

Distribusi pada tabel 3 menjelaskan bahwa sebagian besar responden tinggal di Kecamatan Paal 2 sebanyak 6 orang dengan presentase $(18.8 \%)$.

Tabel 4. Uji Normalitas

\begin{tabular}{lllcc}
\hline \multirow{2}{*}{$\begin{array}{c}\text { Pendidikan } \\
\text { kebencanaan }\end{array}$} & \multicolumn{3}{c}{ Shapiro-Wilk } \\
\cline { 2 - 5 } Hasil & Statistic & Df & Sig. \\
\hline prest intervens & .839 & 16 & .009 \\
pretest control & .884 & 16 & .044 \\
posttest control & .697 & 16 & .000 \\
\hline
\end{tabular}

Sumber: Data Primer 2019

Uji normalitas pada tabel 4 menjelaskan bahwa distribusi data tidak normal. Di karenakan hasil yang di dapat kurang dari nilai $\alpha=0,05$. Selanjutnya peneliti menggunakan uji alternatif menggunakan uji Wilcoxon dan uji Mann whitney.

\section{B. Analisa Univariat}

Tabel 5. Uji Homogenitas

\begin{tabular}{cccc}
\hline $\begin{array}{c}\text { Levene } \\
\text { Statistic }\end{array}$ & Df1 & Df2 & Sg. \\
\hline 0,153 & 1 & 30 & 0,699 \\
\hline
\end{tabular}

Sumber: Data Primer 2019

Uji homogenitas pada tabel 5 diperoleh nilai signifikansi sebesar 0,699. Hal ini berarti distribusi data kelompok intervensi dan kelompok kontrol adalah homogen karena nilai $\alpha>0,05$.

Tabel 6. Distribusi kesiapsiagaan responden pretest dan posttest kelompok intervensi dan kontrol

\begin{tabular}{ccccccccc}
\hline \multirow{2}{*}{ Kategori } & \multicolumn{2}{c}{$\begin{array}{c}\text { Pretest } \\
\text { Intervensi }\end{array}$} & \multicolumn{2}{c}{$\begin{array}{c}\text { Posttest } \\
\text { Intervensi }\end{array}$} & $\begin{array}{c}\text { Pretest } \\
\text { Kontrol }\end{array}$ & \multicolumn{2}{c}{$\begin{array}{c}\text { Posttest } \\
\text { Kontrol }\end{array}$} \\
\cline { 2 - 10 } & $(\mathbf{n})$ & $(\%)$ & $(\mathbf{n})$ & $(\%)$ & $(\mathbf{n})$ & $(\%)$ & $(\mathbf{n})$ & $(\%)$ \\
\hline Siap & 11 & 68.8 & 16 & 100.0 & 10 & 62,5 & 11 & 68.8 \\
Tidak Siap & 5 & 31.3 & 0 & 0 & 6 & 37.5 & 5 & 31.3 \\
\hline Total & 16 & 100.0 & 16 & 100.0 & 16 & 100.0 & 16 & 100.0 \\
\hline Sumber: & Data & Primer & $\mathbf{2 0 1 9}$ & & & &
\end{tabular}

Sumber: Data Primer 2019

Uji statistik pada tabel 6 menunjukkan adanya peningkatan kesiapsiagaan pada kelompok intervensi dari $11 \quad(68,8 \%)$ sebelum diberikan perlakuan, menjadi 16 (100\%) setelah diberikan perlakuan.

Tabel 7. Rerata kesiapsiagaanresponden pretest dan posttest kelompok intervensi dan kontrol

\begin{tabular}{llll}
\hline Variabel & Mean & SD & SE \\
\hline Kelompok Intervensi & & & \\
\hline Pre Test & 17.50 & 2.556 & .639 \\
\hline Post Test & 20 & .000 & .000 \\
\hline Kelompok Kontrol & & & \\
\hline Pre Test & 17.44 & 1.896 & .474 \\
Post Test & 19.50 & .730 & .183 \\
\hline Sumber: Data Primer & 2019 & &
\end{tabular}

Sumber: Data Primer 2019

Berdasarkan pada uji statistik pada tabel 7 menunjukkan bahwa rata-rata kesiapsiagaan pada kelompok intervensi sebelum diberikan perlakuan yaitu 17,50 dengan standar deviasi 2,556. Dan rata-rata kesiapsiagaan setelah diberikan perlakuan yaitu 20 dengan standar deviasi 0,000 . 
Tabel 8. Analisis Pretest-Postest Kesiapsiagaan Responden Kelompok Intervensi

\begin{tabular}{lllll}
\hline Variabel & Mean & SD & Z & $\begin{array}{l}\text { P- } \\
\text { Value }\end{array}$ \\
\hline $\begin{array}{l}\text { Pre Test } \\
\text { Intervensi }\end{array}$ & 17.50 & 2.556 & -2.677 & .007 \\
$\begin{array}{l}\text { Post Test } \\
\text { Intervensi }\end{array}$ & 20 & .000 & & \\
\hline
\end{tabular}

Sumber: Data Primer 2019

Uji Wilcoxon pada tabel 8 terlihat perbedaan nilai mean sebelum dilakukan perlakuan yaitu sebesar 17.50 dan meningkat menjadi 20 setelah dilakukan perlakuan dengan nilai p-value 0,007 $(\leq 0,05)$. Dengan demikian dapat disimpulkan bahwa terdapat perbedaan rerata kesiapsiagaan sebelum dan sesudah diberikan pendidikan kebencanaan pada kelompok intervensi. Dan menunjukkan adanya pengaruh yang signifikan Pendidikan kebencanaan terhadap kesiapsiagaan pada kelompok intervensi.

\section{Analisa Bivariat}

Tabel 9. Analisis Pretest-Postest Kesiapsiagaan Responden Kelompok Kontrol

\begin{tabular}{ccccc}
\hline Variabel & Mean & SD & $\mathbf{Z}$ & $\begin{array}{l}\text { P- } \\
\text { Value }\end{array}$ \\
\hline $\begin{array}{c}\text { Pre Test } \\
\text { Kontrol }\end{array}$ & 17.44 & 1.896 & -2.839 & .005 \\
$\begin{array}{c}\text { Post Test } \\
\text { Kontrol }\end{array}$ & 19.50 & .730 & & \\
\hline
\end{tabular}

Sumber: Data Primer 2019

Nilai rata-rata uji Wilcoxon pada tabel 9 terlihat perbedaan nilai mean sebelum dilakukan perlakuan yaitu sebesar 17.44 dan meningkat menjadi 19,50 setelah dilakukan perlakuan dengan nilai p-value $0,005(\leq 0,05)$. Dengan demikian dapat disimpulkan bahwa terdapat perbedaan rerata kesiapsiagaan sebelum dan sesudah diberikan pendidikan kebencanaan pada kelompok kontrol. Dan menunjukkan adanya pengaruh yang signifikan Pendidikan kebencanaan terhadap kesiapsiagaan pada kelompok kontrol.
Tabel 10. Analisis Perbedaan Rerata Kesiapsiagaan Posttest pada Kelompok Intervensi dan Kelompok Kontrol

\begin{tabular}{llll}
\hline Variabel & $\begin{array}{l}\text { Mean } \\
\text { Rank }\end{array}$ & $\mathbf{Z}$ & p-value \\
\hline Post Intervensi & 23,50 & $-4,665$ & .000 \\
Post Kontrol & 9,50 & & \\
\hline
\end{tabular}

Sumber: Data Primer 2019

Analisis perbedaan pada tabel 10 menunjukkan nilai rata-rata kesiapsiagaan pada posttest kelompok intervensi yang diberikan penyuluhan dan pelatihan simulasi darurat adalah 23,50. Sedangkan nilai rata-rata kesiapsiagaan posstest kelompok kontrol yang tidak diberikan penyuluhan dan pelatihan simulasi gawat darurat adalah 9,50. Hasil nilai p-value 0,000 . Yang berarti didapatkan perbedaan rerata kesiapsiagaan antara kelompok intervensi yang diberikan penyuluhan serta pelatihan simulasi darurat dan kelompok kontrol yang tidak diberikan perlakuan. Hasil ini menjelaskan adanya pengaruh Pendidikan kebencanaan banjir bandang terhadap kesiapsiagaan mahasiswa.

\section{A. Karakteristik Responden}

Penelitian ini dilakukan di Program Studi Ilmu Keperawatan FK Unsrat pada bulan Desember 2018 yang membahas tentang pengaruh pendidikan kebencanaan banjiir bandang terhadap kesiapsiagaan mahasiswa Program Studi Ilmu Keperawatan FK Unsrat dengan jumlah sampel pada penelitian ini berjumlah 32 responden yang telah memenuhi kriteria inklusi. Hasil penelitian menunjukkan dari jumlah responden sebanyak 32 orang, didapati sebagian besar responden berumur $>17$ tahun berjumlah 26 responden $(81,3 \%)$. Tahapan perkembangan remaja menurut Mapiarre (2012) berlangsung antara umur 12 tahun sampai 22 tahun yaitu umur 12 tahun sampai 21 tahun bagi wanita dan 13 tahun sampai 22 tahun bagi pria. Rentang usia remaja ini dibagi menjadi dua bagian yaitu remaja awal yang umurnya antara 12 
tahun sampai 17 tahun dan remaja akhir yang umurnya 17 sampai 21 tahun.

Karakteristik responden berdasarkan jenis kelamin menunjukkan sebagian besar responden adalah perempuan yang berjumlah 26 orang (90,6\%). Hal tersebut dikarenakan jumlah mahasiswa di PSIK FK Unsrat yang masuk dalam kriteria inklusi, laki-laki hanya berjumlah 3 orang. Dan ini juga menjelaskan bahwa penerimaan mahasiswa di PSIK FK Unsrat pada umumnya mahasiswa yang di terima adalah berjenis kelamin perempuan. Karakteristik responden berdasarkan daerah tempat tinggal, semua responden masuk kriteria tinggal di derah rawan bencana, namun sebagian besar responden bertempat tinggal di kecamatan paal 2 yaitu sebanyak 6 orang, dengan presentase $18,8 \%$.

\section{B. Analisa Univariat \\ 1. Kesiapsiagaan}

Hasil penelitian menunjukkan bahwa rerata kesiapsiagaan kelompok intervensi sebelum dan sesudah diberikan parlakuan lebih besar dari kelompok kontrol. Dari hasil penelitian yang hanya sedikit perbedaan rerata kesiapsiagaan dari kedua kelompok ini, peneliti berasumsi yang menjadi pengaruh perbedaan yang sedikit itu karena setiap responden yang sudah dibagi dalam kelompok intervensi dan kontrol, sebagian responden sudah pernah mengalami atau punya pengalaman dengan bencana banjir bandang, hal ini yang mempengaruhi kesiapsiagaan responden dari kedua kelompok tersebut. Namun kelompok intervensi menunjukkan kesiapsiagaan yang lebih baik karena diberikan penyuluhan dan pelatihan simulasi darurat.

Penelitian yang dilakukan oleh Jati (2013) tentang Kesiapsiagaan Masyarakat Terhadap Bencana Banjir Di Kelurahan Jagalan Kecamatan Jebres Kota Surakarta yang hasil penelitian menunjukkan tingkat kesiapsiagaan yang baik dari masyarakat dalam menghadapi banjir. Penelitian ini juga sejalan dengan hasil penelitian dari
Febriana (2015) tentang Kesiapsiagaan Masyarakat Desa Siaga Bencana Dalam Menghadapi Bencana di Kota Banda Aceh menunjukkan hasil kesiapsiagaan dari masyarakat baik, kesamaan penelitian Febriana dan penelitian ini adalah setelah dilakukan pelatihan simulasi darurat kepada kelompok intervensi, kesiapsiagaan kelompok intervensi masuk dalam kategori baik.

\section{Analisa Bivariat}

1. Pengaruh Pendidikan Kebencanaan Banjir Bandang Terhadap Kesiapsiagaan

Analisis hasil hipotesa dari pendidikan kebencanaan banjir bandang terhadap kesiapsiagaan menggunakan uji Wilcoxon (untuk melihat pengaruh pretestpostest) dan uji Mann Withney (untuk melihat pengaruh posttest-postest). Pada tingkat kemaknaan $95 \%(\alpha=0,05)$, dari hasil penelitian yang telah dilakukan menunjukkan adanya pengaruh yang signifikan antara pendidikan kebencanaan banjir bandang dengan kesiapsiagaan mahasiswa program studi ilmu keperawatan FK Unsrat. Diman nilai $\mathrm{p}$-Value $=0,000$ kurang dari $\alpha=0,05$. Dari hasil penelitian ini, peneliti berasumsi, bahwa pendidikan kebencanaan sangat mempengaruhi kesiapsiagaan seseorang. Tingkat pengetahuan dan kesiapppsiagaan seseorang bisa di pengaruhi dari setiap informasi dan pengalaman yang dialami, tapi sangat besar pengaruhnya jika pelatihan simulasi darurat di mobilisasi langsung oleh setiap orang. Dan kemaknaan pendidikan kebencanaan berupa penyuluhan akan lebih di mengerti oleh sesorang jika diberikan secara langsung.

Penelitian ini sejalan dengan hasil penelitian yang ditunjukkan oleh Saanun (2017) tentang Pengaruh Penyuluhan Kesehatan terhadap Kesiapsiagaan Dalam Menghadapi Bencana Tanah Longsor Pada Siswa Kelas XI SMKN 6 Manado, yang hasilnya menunjukkan adanya pengaruh penyuluhan kesehatan terhadap kesiapsiagaan dalam menghadapi bencana 
tanah longsor pada siswa kelas XI SMKN 6 Manado. Ini menjelaskan bahwa benar, pendidikan kebencanaan bisa juga memberi pengaruh terhadap kesiapsiagaan seseorang, sebagai bentuk antisipasi akan adanya bencana yang terjadi. Adapun penelitian oleh Widjanarko (2018) menunjukkan hasil yang berbeda, dalam penelitiannya tentang Pengaruh Pendidikan Bencana Pada Perilaku Kesiapsiagaan Siswa, hasilnya menunjukkan tidak adanya pengaruh pendidikan bencana terhadap kesiapsiagaan siswa dalam menghadapi bencana. Peneltian Mochamad ini terdapat beberapa kelemahan diantaranya, pertama pelaksanaan pendidikan bencana yang tidak terjadwal dengan rutin seminggu sekali menjadikan subjek yang masih dalam perkembangan anak-anak menjadi belum terbiasa, lupa dengan apa yang sudah di informasikan dalam pertemuan sebelumnya. Kedua, subjek terkadang tidak teringat dalam berperilaku kesiapsiagaan menghadapi bencana dan belum pernah mengikuti kegiatan penginformasian kesiapsiagaan akan bencana yang dilakukan pihak sekolah pada siswa.

\section{SIMPULAN}

1. Adanya pengaruh pendidikan kebencanaan terhadap kesiapsiagaan mahasiswa Program Studi Ilmu Keperawatan FK Unsrat.

2. Sebelum dilakukan penyuluhan dan pelatihan simulasi darurat, kesiapsiagaan responden kedua kelompok sebagian besar belum siap.

3. Setelah dilakukan penyuluhan dan pelatihan simulasi darurat kesiapsiagaan dari kedua kelompok berbeda, tingkat kesiapsiagaan kelompok intervensi lebih baik dari pada kelompok kontrol.

4. Hasil penelitian menunjukkan adanya perbedaan yang signifikan antara kelompok intervensi dan kelompok kontrol sebelum dan sesudah diberikan penyuluhan dan pelatihan simulasi darurat. Hal ini berarti, ada pengaruh pendidikan kebencanaan banjir bandang terhadap kesiapsiagaan mahasiswa Program Studi Ilmu Keperwatan FK Unsrat.

\section{DAFTAR PUSTAKA}

Adi S. (2014). Karakterisasi Bencana Banjir Bandang Di Indonesia. Jurnal Sains dan Teknologi Indonesia 15 (1), 45.

Badan Nasional Penanggulangan Bencana, 2011. Peraturan Kepala Badan Nasional Penanggulangan Bencana Nomor 8 Tahun 2011 Tentang Standardisasi Data Kebencanaan. Badan Nasional Penanggulangan Bencana, Jakarta, 2011.

Departemen Kesehatan (2006). Sumber Daya Manusia Dalam Kesiapsiagaan.

Febriana (2015). Kesiapsiagaan Masyarakat Desa Siaga Bencana Dalam Menghadapi Bencana Gempa Bumi Di Kecamatan Meuraxa Kota Banda Aceh. Jurnal Ilmu Kebencanaan.

Ghozali I. (2009). Statistik Non Parametik Teori Dan Aplikasi Dengan Program BM SPSS 23.

Hendrik K. (2016). Identifikasi Penggunaan Lahan Pada Daerah Rawan Banjir Bandang Kota Manado. Thesis : Universitas Sam Ratulangi Manado.

Ilmu Geografi Indonesia. Banjir Bandang : Pengertian, Karakteristik, Penyebab dan Dampaknya. Mei 2016.

Jacklin S (2015). Pengaruh Penyuluhan Bencana Banjir Terhadap Kesiapsiagaan Siswa SMP Katolik Soegiyo Pranoto Manado Menghadapi Bencana. Skripsi : Universitas Sam Ratulangi

Jati T. (2013). Kesiapsiagaan Masyarakat Terhadap Bencana Banjir di Kelurahan Jagalan Kecematan Jebres. Naskah Publikasi : 
e-journal Keperawatan (e-Kp) Volume 7 Nomor 1, 4 April 2019

Univetsitas Muhammadiyah

Surakarta.

Kurniati A. \& Trisyani Y. \& Theresia S. Keperawatan Gawat Darurat dan Bencana Sheehy.

Laluyan (2012). Dampak Psikologis Banjir

Bandang bagi Warga

Perkambungan Batu Merah dan

Kawasan Wayori di Ambon. Studi

Perbandingan : UKSW Yogyakarta.

Mappiare A (2012). Psikologi Remaja. Surabaya: Usaha Nasional

Notoatmodjo, S. (2010). Metodologi

Penelitian Kesehatan. Jakarta:

Rineka Cipta.

Pikiran Rakyat (2016). Penanganan Dampak Psikologis Korban Bencana Alam.

Ruswandi, D. (2014). Indeks Resiko Bencana Indonesia. Direktorat Pengurangan Risiko Bencana Deputi Bidang Pencegahan dan Kesiapsiagaan : Indonesia

Saanun F (2017). Pengaruh Penyuluhan Kesehatan Terhadap Kesiapsiagaan Dalam Menghadapi Bencana Tanah Longsor Pada Siswa XI SMK Negeri 6 Manado. Jurnal Keperawatan : Universitas Sam Ratulangi.

Septian F (2017). Pengaruh Terapi Seft (Spiritual Emotional Freedom Technique) Terhadap Penurunan Skor Desakan Untuk Merokok Pada Siswa SMPN 1 Kasihan, Bantul.

Widjanarko M. (2018). Pengaruh Pendidikan Bencana Pada Perilaku Kesiapsiagaan Siswa. Jurnal Ecopsy : Universitas Muria Kudus. 